\title{
Sezgisel Algoritmalar Kullanılarak İki Boyutlu Dikdörtgen Şerit Paketleme Probleminin Çözümü
}

\author{
Hüseyin Frrat ${ }^{1 *}$, Nuh Alpaslan ${ }^{2}$ \\ 1 İskenderun Teknik Üniversitesi, Dörtyol MYO, Bilgisayar Teknolojileri Bölümü, Hatay, Türkiye (ORCID: 0000-0002-1257-8518) \\ ${ }^{2}$ Bingöl Üniversitesi, Mühendislik ve Mimarlık Fakültesi, Bilgisayar Mühendisliği Bölümü, Bingöl, Türkiye (ORCID: 0000-0002-6828-755X)
}

(Illk Geliş Tarihi 16 Eylül 2019 ve Kabul Tarihi 22 Ekim 2019)

(DOI: 10.31590/ejosat.620618)

ATIF/REFERENCE: Firat, H. \& Alpaslan, N. (2019). Sezgisel Algoritmalar Kullanılarak İki Boyutlu Dikdörtgen Şerit Paketleme Probleminin Çözümü. Avrupa Bilim ve Teknoloji Dergisi, (17), 315-322.

\section{Öz}

Bu çalışmada, alt sol dolgu, ilk uygun azalan ve uygun olmayan çokgen sezgisel algoritmaları kullanılarak iki boyutlu dikdörtgen şerit paketleme probleminin çözümü üzerine bir yöntem önerilmektedir. İki boyutlu dikdörtgen şerit paketleme problemi (2D-SPP), sabit genişlik ve sonsuz yüksekliğe sahip bir şerit üzerine bir dizi dikdörtgen parçanın yerleştirilmesidir. Amaç, tüm dikdörtgenleri tamamen şeridin içine yerleştirmek için gereken yüksekliği en aza indirgemektir. Bu problemin çözümünde, yerleştirme işlemi için alt sol dolgu algoritması, dikdörtgen parçalar arasında oluşabilecek çakışmayı önlemek için uygun olmayan çokgen yöntemi kullanılmıştır. Ayrıca, parçalar alanlarına göre azalan sırada sıralandıktan sonra yerleştirme işlemi için kullanılacak olan seçim algoritması olarak da ilk uygun azalan sezgisel algoritması kullanılmıştır. 21 farklı veri seti üzerinde çalışmalar gerçekleştirilmiş ve performans değerlendirilmesi yapılmıştır. Gerçekleştirilen deneysel çalışmalar sonucunda optimal çözüme yakın sonuçlar elde edilmiştir. Deneysel sonuçlar, 2D-SPP için önerilen sezgisel yöntemlerin etkinliğini göstermektedir.

Anahtar Kelimeler: Alt-sol dolgu algoritması, Uygun olmayan çokgen yöntemi, İlk uygun azalan sezgisel algoritması, Şerit paketleme problemi

\section{Solution of Two Dimensional Rectangular Strip Packing Problem Using Heuristic Algorithms}

\begin{abstract}
In this study, a method is proposed for the solution of two-dimensional rectangular strip-packing problem by using bottom-left fill, first-fit decreasing and no-fit polygon heuristic algorithms. The two-dimensional rectangular strip-packing problem (2D-SPP) is the placement of a series of rectangular pieces on a strip with a constant width and infinite height. The goal is to minimize the height required to completely place all the rectangles onto the strip. In order to solve this problem, the bottom-left fill algorithm is used for the placement process and the no-fit polygon method is used to prevent the overlap between the rectangular parts. In addition, after the parts are sorted in descending order by areas, the first-fit decreasing heuristic algorithm is used as the selection algorithm for the placement process. The study has been carried out on 21 different data sets and performance evaluation has been done. As a result of conducted experimental studies, near to optimal solutions were obtained. The experimental results show the effectiveness of the proposed heuristic methods for 2D-SPP.
\end{abstract}

Keywords: Bottom-left fill algorithm, No-fit polygon method, First fit decreasing heuristic algorithm, Strip packing problem.

\footnotetext{
* Sorumlu Yazar: İskenderun Teknik Üniversitesi, Dörtyol MYO, Bilgisayar Teknolojileri Bölümü, Hatay, Türkiye, ORCID: 0000-0002-12578518, huseyin.firat@iste.edu.tr
} 


\section{Giriş}

Günümüzde, endüstriyel rekabet edebilirlik için, üretim sürecinde malzemelerin kesilmesi veya paketlenmesi ile ilgili çalışmalar dâhil, üretim sürecini optimize etmek finansal yatırım gerektirmektedir. Kesme veya paketleme işlemleri sırasında ham madde atığının azaltılması, farklı endüstriyel sektörlerde maliyet düşüşünü göstermektedir. Endüstriyel bağlama bakılmaksızın, katı malzemelerin daha küçük parçalar halinde kesilmesi veya boş alanlardaki maddelerin paketlenmesi aynı mantıksal yapıdaki optimizasyon problemleridir. Temel amaç, tüm sorun kısıtlamalarını karşılayan atığı en aza indiren büyük nesnelerdeki (büyük ham madde yüzeyleri) küçük parçaların en iyi çeşitliliğini bulmaktır [1].

Kesme ve paketleme problemleri, farklı kısıtlamalar ve nesneler içeren farklı uygulamalarla otomotiv, deri, cam kesme, ahşap, tekstil, hazır giyim imalatı, çok işlemcili görev çizelgeleme, kargo yükleme ve entegre devre tasarımı gibi birçok endüstriyel uygulama alanı bulmaktadır [2]. Örneğin, ahşap veya cam endüstrilerinde, dikdörtgen bileşenlerin büyük malzeme tabakalarından kesilmesi gerekmektedir. Gazete sayfalarında, sayfalardaki makaleler ve reklamlar düzenlenmelidir. Kesme ve paketleme problemleri NP-Hard olarak tanımlanır, kesin yöntemler kullanarak kesme ve paketleme problemlerini hesaplamak özellikle çok sayıda ürün içeren büyük nesnelerde paketleme işlemi hesapsal olarak oldukça maliyetlidir.

Kesme ve paketleme problemleri ile ilgili literatürde birçok çalışma bulunmaktadır. Bu problemler, farklı uygulamalarda ortaya çıkabilmekte ve farklı amaç ve kısıtlara sahip olabilmektedir. Problemin farklı versiyonlarını sınıflandırmak için Wäscher tarafından bir tipoloji önerilmekte ve bu tipoloji literatüre önemli katkı sağlamaktadır. Kesme ve paketleme problemleri tipolojisinde, ilgili problem tiplerini kategoriler halinde sınıflandırmak için farklı kriterler kullanılmaktadır. Bu kriterler, boyut, görev türü, küçük parçaların çeşitliliği, büyük nesne çeşitliliği ve küçük parçaların şekli olarak sıralanmaktadır. Boyut, problemin ilgili boyutlarının (1D-2D-3D) sayısını dikkate almaktadır. Görev türü, amaç fonksiyonunun oryantasyonu ile ilgilenmektedir (çıktı değeri maksimizasyonu veya girdi değeri minimizasyonu). Şekil çeşitliliği ve boyutu (aynı şekiller, az sayıda aynı ve farklı şekiller, çok sayıda aynı şekil ve birkaç farklı şekil, birçok aynı ve birçok farklı şekil), küçük parçaların çeşitlerini tanımlamaktadır. Benzer şekilde, büyük nesnelerin çeşitliliği için bir nesnenin (sabit boyut ve değişken boyutta olan) veya sabit boyutlara sahip birkaç büyük nesnenin (özdeş nesneler, zayıf heterojen veya güçlü heterojen) boyutlarının ve şekillerinin değişimleri göz önünde bulundurulmaktadır. Son olarak, yerleşim işlemi için kullanılacak parçalar/şekiller düzenli (dikdörtgen veya daireler) veya düzensiz şekillere sahip olabilmektedir [3].

İki boyutlu dikdörtgen şerit paketleme problemi ise, atıkların (büyük nesnenin kullanılmayan bölgeleri) minimize edilmesi için, küçük nesnelerin büyük bir nesneden kesilmesi veya büyük nesne üzerine paketlenmesi gereken genel kesme ve paketleme problemleri sınıfı içerisinde yer almaktadır. 2D-SPP, iyi bilinen birleştirici optimizasyon problemidir. Rulo kâğıtların, ahşap ve çelik levhaların veya tekstil malzemelerinin kesilmesi gibi çeşitli endüstriyel uygulamalarda kullanılmaktadır. Bu problemler, tüm öğelerin dikdörtgen olduğu ve bu nedenle tam olarak bir genişlik ve yükseklik ile karakterize edilen özel kesme ve paketleme problemlerine yaklaşmakta ve yerleştirme için kullanılan büyük nesne bir şerit, yani sabit genişlikte fakat sonsuz bir yüksekliğe sahip bir dikdörtgendir. Bu problemlerin amacı, tüm dikdörtgenleri şerit üzerine yerleştirerek yüksekliği en aza indirgemektir. Bu problemler, klasik kesme ve paketleme problemlerinin bir alt kümesi olduklarından, NP-Hard problemler olarak tanımlanmaktadırlar [4]. 2D-SPP problemleri çözmek için, literatürde farklı metodolojilere sahip çeşitli sezgisel ve meta-sezgisel algoritmalar sunulmaktadır. [5] nolu çalışmada, dikdörtgen şerit paketleme problemi için ikili arama sezgisel algoritması anlatılmıştır. İlk önce optimizasyon problemi bir karar problemine dönüştürülmüştür. İlgili karar problemini çözmek için en az atık harcayan bir strateji ve en az salınan bir ilk strateji önerilmiştir. Son olarak, orijinal optimizasyon problemini çözmek için rastgele yerel aramaya dayalı bir ikili arama sezgisel algoritması geliştirilmiştir. Altı karşılaştırmalı sınıf probleminin hesaplamalı sonuçları, sunulan algoritmanın, sıfır atık örneklerin çoğu için yayınlanan en iyi sezgisel algoritmalardan daha makul bir sürede daha iyi çözümler bulabildiği gösterilmiştir. [6] nolu çalışmada, iki boyutlu dikdörtgen şerit paketleme problemi için içbükey köşe stratejisine göre en uygun yöntemi anlatılmıştır ve bu yöntem literatürdeki sezgisel ve metasezgisel yöntemler ile karşılaştırılmıştır. Geliştirilmiş olan yöntemin 50 ve daha fazla parça yerleşimi için daha iyi paketleme düzenleri üretilebileceği ve kısa sürede daha iyi sonuçlar alınacağı gösterilmiştir. [7] nolu çalışmada, yönlendirilmemiş 2D-SPP'yi çözmek için fruit fly optimizasyon algoritması (FOA) kullanılarak bir çözüm sunulmuştur. Çalışmanın amacı, şeritlerin içindeki dikdörtgenlerin optimal dizisini bulmak ve sonra dikdörtgenleri, sabit genişlikli bir kutu içerisinde optimal yüksekliğe sahip olacak şekilde alt sol dolgu yaklaşımıyla yerleştirmektir. Deneyler çevrimiçi olarak sunulan 2D-SPP test problemleri seti üzerinde sonuçlandırılmıştır. Çalışmanın ön sonuçları, aynı problem kümesini kullanan bazı geleneksel ya da sezgisel yaklaşımların sonuçlarıyla karşılaştırılmıştır. Deneysel sonuçlar ile 2D-SPP'lerin çözülmesi için FOA tarafından elde edilen sonuçların iyi olduğu gösterilmiştir.

$\mathrm{Bu}$ çalışmada ise, alt sol dolgu, ilk uygun azalan ve uygun olmayan çokgen sezgisel algoritmaları kullanılarak iki boyutlu dikdörtgen şerit paketleme problemine çözüm sunulmuştur. Çalışmadaki temel amaç, sabit genişlikte ve sınırsız yükseklikte bir şerit/levha üzerine yerleştirme işlemi için kullanılacak bir dizi dikdörtgen parçanın tamamını yerleştirerek yüksekliği minimize etmek ve buna bağlı olarak verimi maksimize etmektir.

Bu çalışma kapsamında, ilk bölümde kesme ve paketleme problemleri ile şerit paketleme problemi hakkında bilgiler verilmiş ve şerit paketleme problemi ile ilgili literatürde yapılmış olan çalışmalardan bazıları açıklanmıştır. İkinci bölümde şerit paketleme probleminin tanımı yapılmıştır. Üçüncü bölümde, uygulama kapsamında kullanılan veri seti, yöntemler ve önerilen yöntem açıklanmıştır. Dördüncü bölümde, uygulama sonuçları ve beşinci bölümde ise sonuçlara yer verilmiştir. 


\section{2D-SPP Problemi}

Sabit genişlikte dikdörtgen bir şerit/levha ve rasgele boyutlarda bir dizi dikdörtgen parça verilmişse, dikdörtgenlerin şerit paketleme problemi, verilen tüm dikdörtgenleri şerit üzerine yerleştirmekte ve kullanılan şeridin yüksekliğini minimize etmeyi amaçlamaktadır. $W$ şeridin genişliğini, $H$ şeridin sınırsız yüksekliğini, $W$ ve $h$ ise yerleştirme işlemi için kullanılacak olan dikdörtgen parçaların sırasıyla genişlik ve yüksekliğini temsil etmektedir. $P=\left\{p_{i}\left(w_{i}, h_{i}\right), i=1,2,3 \ldots \ldots \ldots n\right\} n$ tane yerleştirilecek dikdörtgen dizisini ifade etmektedir. Paketleme işlemi yapılırken şu kısıtlamalar yerine getirilmelidir: Her $p_{i}$ dikdörtgen parçası genişliği $w_{i}$ ve yüksekliği $h_{i}\left(w_{i}, h_{i} \in Z^{+}\right)$olan ve genişliği $W$ 'dan büyük olmayan en az bir kenara sahiptir. Paketlenmiş dikdörtgenlerin her bir kenarı, aynı zamanda dikey paketleme olarak da adlandırılan bir kenara paralel olmalıdır ve herhangi iki paketlenmiş dikdörtgen birbirinin üstüne gelmemelidir. Algoritmanın amacı, tüm parçaları dikey veya yatay olarak şeridin üzerine paketlemektir. Yerleştirme işlemi yapılırken parçalar $90^{\circ}$ döndürülebilmekte, aynı zamanda şeridin kullanılan $H$ yüksekliği Şekil 1'de gösterildiği gibi iki parça arasında çakışma olmadan minimize edilmektedir.

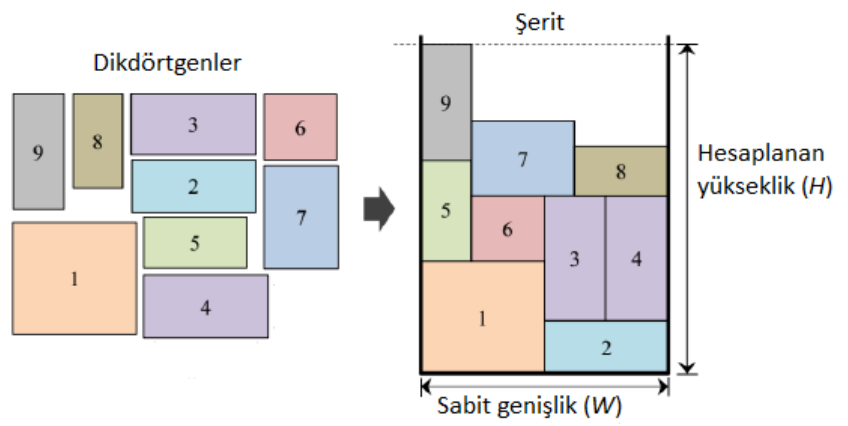

Şekil 1. 2D-SPP'nin genel görünümü [1]

Problemin matematiksel formülasyonu ise şu şekilde tanımlanabilir: $\boldsymbol{W}$ genişliğinde ve $\boldsymbol{H}$ yüksekliğinde şerit/levha üzerine, $\boldsymbol{w}_{\boldsymbol{i}}$ genişliğinde ve $\boldsymbol{h}_{\boldsymbol{i}}(\mathbf{1} \leq \boldsymbol{i} \leq \boldsymbol{n})$ yüksekliğinde $\boldsymbol{n}$ tane dikdörtgen parçanın paketlenme probleminde, her bir dikdörtgenin şerit üzerine paketlenip paketlenmediğini kontrol etmek $\boldsymbol{f}_{\boldsymbol{i}}$ ile gösterilsin. $\boldsymbol{f}_{\boldsymbol{i}}=\mathbf{1}$ ise paketleme işlemi gerçekleşmiş, $\boldsymbol{f}_{\boldsymbol{i}}=\mathbf{0}$ ise paketleme işlemi gerçekleşmemiştir. Şerit üzerine yerleştirilecek her dikdörtgen $\boldsymbol{p}_{\boldsymbol{i}}$ için, $\left(\boldsymbol{x}_{\boldsymbol{l}}, \boldsymbol{y}_{\boldsymbol{l}}\right)$ sol alt köşenin koordinatlarını, ( $\left.\boldsymbol{x}_{\boldsymbol{r} i}, \boldsymbol{y}_{\boldsymbol{r} i}\right)$ sağ üst köşenin koordinatlarını belirtsin.

$$
\begin{gathered}
\max \sum_{i=1}^{n} f_{i} w_{i} h_{i} \\
\left(0 \leq x_{l i} \leq x_{r i} \leq \mathrm{W} \text { or } 0 \leq y_{l i} \leq y_{r i} \leq \mathrm{H}\right) \quad(i=1,2, \ldots \ldots, n) \\
\left(x_{r i}-x_{l i}=w_{i} \wedge y_{r i}-y_{l i} \leq h_{i}\right) \text { or }\left(x_{r i}-x_{l i}=h_{i} \wedge y_{r i}-y_{l i} \leq w_{i}\right) \quad(i=1,2, \ldots \ldots, n) \\
\left(x_{l i} \geq x_{r j} \text { or } x_{l j} \geq x_{r i} \text { or } y_{l i} \geq y_{r j} \text { or } y_{l j} \geq y_{r i}\right) \quad(i=j=1,2, \ldots, n)(i \neq j) \\
f_{i} \in\{0,1\} \quad(i=1,2, \ldots, n)
\end{gathered}
$$

Denklem 1, paketleme işlemi için kullanılan dikdörtgen parçaların yerleştirilmesi sonucunda elde edilen verimlilik değerinin hesaplanması için kullanılmaktadır. Denklem 2, her dikdörtgenin şeridin sınırları içine yerleştirilmiş olduğu anlamına gelmektedir. Denklem 3, paketlenecek olan dikdörtgenlerin dönebilir olduğunu, Denklem 4, paketlenecek olan dikdörtgenlerin birbiri ile örtüşmeyeceğini ve Denklem 5 ise, paketleme işlemi için kullanılacak olan her bir dikdörtgenin paketlenip paketlenmeyeceğini belirtmektedir.

\section{Materyal ve Metot}

\subsection{Veri Seti}

Test amacıyla Hopper ve Turton tarafından sunulan veri seti bu çalışmada kullanılmıştır [8]. Bu veri setinde 7 sınıfta 21 örnek bulunmakta ve her problem sınıfında ise 3 örnek vardır. Problem veri seti Tablo 1'de gösterilmiştir. 
Tablo 1. Kullanılan veri setinin gösterimi

\begin{tabular}{|cccc|}
\hline Sunuf & $\begin{array}{c}\text { Dikdörtgenlerin } \\
\text { sayust }\end{array}$ & Genişlik & $\begin{array}{c}\text { Optimal } \\
\text { yükseklik }\end{array}$ \\
\hline C1 & 16 veya 17 & 20 & 20 \\
\hline C2 & 25 & 40 & 15 \\
\hline C3 & 28 veya 29 & 60 & 30 \\
\hline C4 & 49 & 60 & 60 \\
\hline C5 & 72 veya 73 & 60 & 90 \\
\hline C6 & 97 & 80 & 120 \\
\hline C7 & 196 veya 197 & 160 & 240 \\
\hline
\end{tabular}

\subsection{Alt Sol Dolgu Yerleşim Yöntemi}

2D-SPP çözümünde, dikdörtgenlerin yerleşimi için kullanılan yerleşim yöntemidir. Alt sol dolgu yerleşim yöntemi, yerleşim modelinde mevcut boş alanlara uygun parçaların yerleştirildiği bir yöntemi kapsamaktadır. Bu algoritma, Şekil 2'de gösterildiği gibi parçaları daha önce konumlandırılmış olanlarla örtüşmeden, yerleştirme işleminin yapılacağı yüzeyin alt sol yerine mümkün olduğu kadar sırayla ve boşlukları doldurarak yerleştirmeyi içermektedir. Şekil 2'de 1'den 7'ye kadar olan parçalar yerleştirildikten sonra 8 numaralı parçanın yerleşimi alt sol dolgu algoritmasıyla mevcut boşluğa yerleştirilmiştir [9].

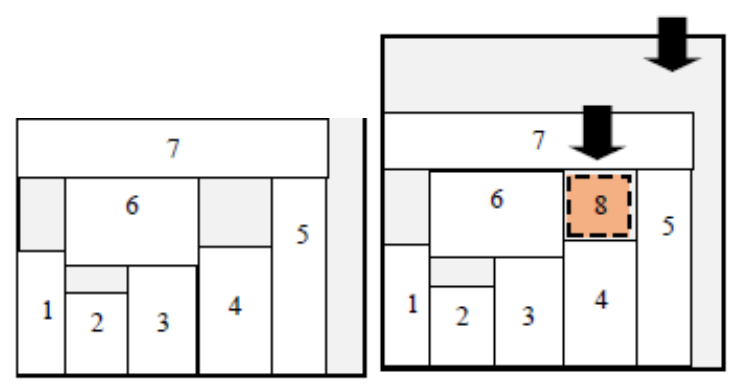

Şekil 2. Alt sol dolgu yerleşim yöntemi [9]

\subsection{Uygun Olmayan Çokgen Yöntemi}

Uygun olmayan çokgen (No-fit polygon/NFP) yöntemi, 2D-SPP için yerleştirilecek olan dikdörtgen parçalar arasında çakışma olup olmadığını test etmek için kullanılan güçlü bir yapıdır. Uygun olmayan çokgen yönteminin ana işlevi, iki çokgenin kesiştiği bölgeyi tanımlamaktır. Diğer bir deyişle, iki çokgenin çakışmasını önlemektir. Şekil 3 ’teki örnek, uygun olamayan çokgen yapısına genel bir bakış sunmaktadır.

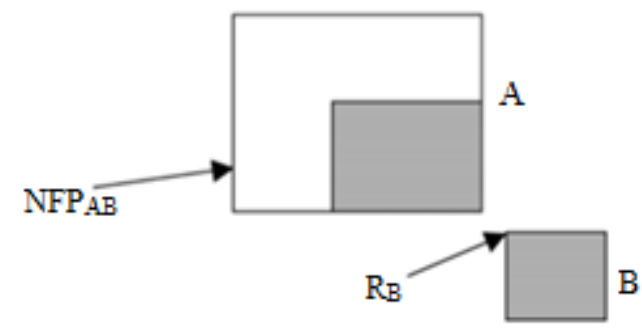

Şekil 3. Uygun olmayan çokgen gösterimi

İki dikdörtgen şekil A ve B göz önüne alındığında, uygun olmayan çokgen, bir şeklin diğer şeklin sınırı etrafında izlenmesiyle bulunabilmektedir. Dikdörtgen şekillerden biri yerinde sabit kalırken, diğer şekil ise sabit şekil etrafında hareket etmektedir. Ancak bu hareket sırasında şekiller birbirlerine dokunmasına rağmen asla kesişmezler. Şekil 3’te gösterildiği gibi ilk dikdörtgen şekil (A) sabit olduğu kabul edilirken, ikinci dikdörtgen şekil (B), sabit şekil (A) etrafındaki yörüngede olduğu kabul edilmektedir. Bundan dolayı B şekli A sabit şekil etrafında dolaştı̆̆ında uygun olmayan çokgen $\mathrm{NFP}_{\mathrm{AB}}$ olarak gösterilmektedir. $\mathrm{NFP}_{\mathrm{AB}}$ oluşturulurken, $\mathrm{B}$ şekli $\mathrm{A}$ şeklinin etrafinda hareket ederken takip edilecek bir referans noktası $\left(R_{B}\right)$ seçilmelidir ve bu referans noktası $B$ dikdörtgen şeklinden seçilmektedir. Referans noktası, yörüngedeki dikdörtgen şeklin hareketlerini izlemesi koşuluyla isteğe bağlı herhangi bir nokta olabilmektedir. Şekil B'nin sabit şekil A ile çakışıp çakışmadığını test etmek için $\mathrm{NFP}_{\mathrm{AB}}$ ve $\mathrm{B}$ şeklinin referans noktası kullanılmaktadır. Eğer şekil B'nin referans noktası $\mathrm{NFP}_{\mathrm{AB}}$ içinde olacak şekilde konumlandırıldıysa, o zaman şekil A ile çakışmaktadır. Referans noktası NFP ${ }_{\mathrm{AB}}$ sınırında ise, şekil B şekil A'ya dokunmaktadır. Ancak bu durum çakışma değildir. Son olarak, referans noktası $\mathrm{NFP}_{\mathrm{AB}}$ 'nin dışındaysa, dikdörtgen şekiller A ve B çakışmamakta veya birbirlerine dokunmamaktadırlar. Dolayısıyla, hesaplanan $\mathrm{NFP}_{\mathrm{AB}}$ 'nin iç kısmı, $\mathrm{A}$ ve $\mathrm{B}$ şekillerinin kesişen tüm konumlarını temsil etmekte ve sınır tüm temas eden konumları temsil etmektedir. 


\section{4. İlk Uygun Azalan Sezgisel Algoritmasi}

İlk uygun azalan sezgisel algoritması, yerleştirilecek olan dikdörtgen parçalar alanlarına göre azalan sırada sıralandıktan sonra seçim algoritması olarak kullanılan algoritmadır. Bu algoritmanın işleyişi şu şekildedir. Öncelikle yerleştirilecek olan dikdörtgenlerin alanları hesaplanır ve azalan sırada sıralanır. Yerleştirme işlemine alanı en büyük olan dikdörtgen parça ile başlanılır. İlk parça yerleştirildikten sonra, ikinci parça için uygun konum bulunur ve ikinci parçanın yerleşimi de gerçekleştirilir. Bu işlem tüm parçalar uygun konumlara yerleşene kadar devam eder [10]. Burada yerleştirme işlemi gerçekleştirilirken, parçaların çakışmama durumu ve yerleştirme işlemi için kullanılan alt sol dolgu algoritmaları da göz önünde bulundurulur. Bu algoritmanın avantajı, bize yerleştirilecek olan dikdörtgen parçaların yerleşim sırasını vermektedir.

\section{5. Önerilen Yöntem}

$\mathrm{Bu}$ çalışmada, üçüncü bölümde anlatılan alt sol dolgu yerleşim yöntemi, uygun olmayan çokgen yöntemi ve ilk uygun sezgisel algoritması kullanılarak iki boyutlu dikdörtgen şerit paketleme problemine çözüm aranmaktadır. Dikdörtgen parçaların yerleşim sırasını elde etmek için ilk uygun azalan sezgisel algoritması kullanılmaktadır ve alt sol dolgu algoritması kullanılarak dikdörtgenlerin paketlenmesi gerçekleştirilmektedir. Dikdörtgen şerit üzerine paketlenecek dikdörtgen parçalar yatay ve dikey olarak yerleştirilebilir. Paketleme işleminde kullanılacak olan parçaların üst üste gelmeden yerleştirme yapılacak şerit üzerine en verimli şekilde yerleştirilmesi sağlanmaktadır. Parçalar 90 derece döndürülebilmektedir. Önerilen yöntemde, dikdörtgen parçaların şerit üzerine paketlenmesi için başlangıç noktası belirlenir. Dikdörtgen parçalar alanlarına göre büyükten küçüğe doğru sıralı olarak ele alınır ve yerleştirme işlemi en fazla alana sahip dikdörtgen ile başlar ve daha sonra yerleştirilecek her dikdörtgen parça alanlarına göre uygun konumlara yerleştirilir. Önerilen yöntem ile geliştirilen uygulamalarda başlangıç noktası sol üst kösse seçilmiştir. Önerilen çözüm yönteminin akış diyagramı Şekil 4 'te gösterilmiş ve algoritma adımları ise aşağıda belirtilmiştir.

Adım 1: Paketleme işlemine başlamadan önce paketleme işleminin yapılacağı şerit/levha, paketleme işleminde kullanılacak olan $n$ tane dikdörtgen parçanın boyutları belirlenmeli ve bunların alanları hesaplanmalıdır.

Adım 2: Paketleme işleminde kullanılacak dikdörtgen parçalar alanlarına göre azalan sırada sıralanır.

Adım 3: Paketleme işlemi için kullanılacak olan parçalar alanlarına göre büyükten küçüğe doğru sıralandıktan sonra paketleme işleminin yapılacağı başlangıç noktası belirlenir.

Adım 4: Parçaların yerleşimi için başlangıç noktası belirlendikten sonra alanı en büyük olan ilk dikdörtgen parçanın yerleşimi gerçekleştirilir. Diğer parçaların yerleşim işleminin yapılması için uygun konumlar belirlenir. Alt-sol dolgu yerleşim algoritması kullanılarak bir yerleşim modeli oluşturulmakta ve dikdörtgen parçaların dönme durumu ile parçalar arasındaki çakışma durumu göz önüne alınarak tüm parçalar yerleştirilinceye kadar paketleme işlemi devam ettirilmektedir.

Adım 5: Tüm dikdörtgen parçaların paketleme işlemi tamamlandıktan sonra elde edilen yükseklik değeri hesaplanmaktadır.

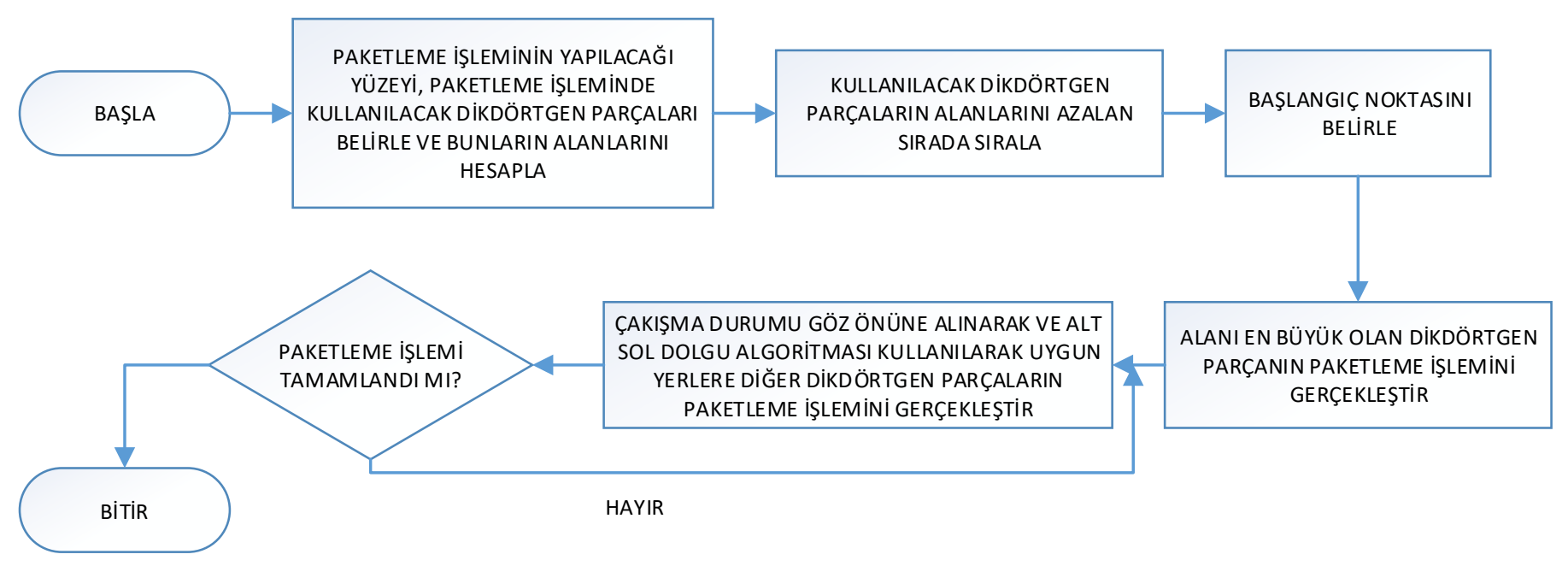

Şekil 4. Önerilen yöntemin akış diyagramı 
Paketleme işlemi için kullanılacak olan şeridin genişliği 40, kullanılacak olan dikdörtgen parçaların boyutları ise $(7,6),(4,4)$, $(40,16),(7,8),(5,20),(4,20),(24,24),(5,4),(7,4),(7,6)$ şeklinde verilmiş olsun. Başlangıç noktası sol üst kösse seçilerek paketleme işlemine başlanmıştır. Önerilen yöntemle geliştirilen örnek uygulamada 10 adet dikdörtgen parçanın yerleşim işlemi Şekil 5 'teki gibidir. Örnek uygulamada şeridin yüksekliği 40 çıkmış ve tüm parçalar şerit üzerine yerleşmiştir.

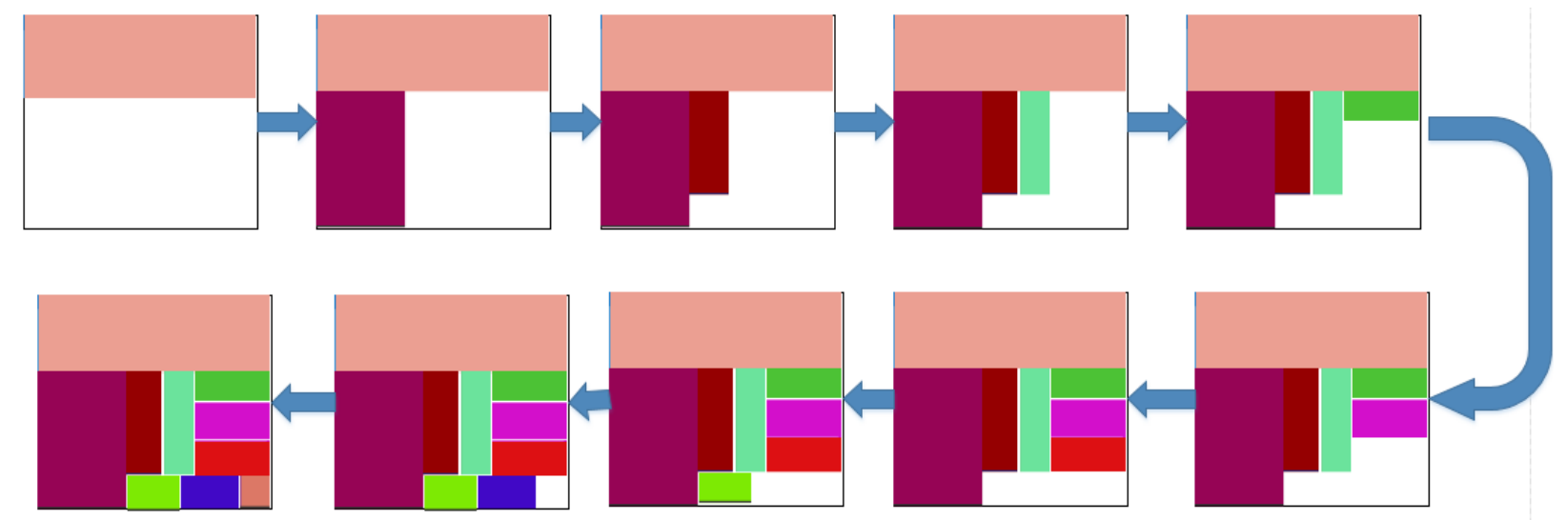

Şekil 5. Önerilen yöntem için geliştirilen örnek uygulama

\section{Araştırma Sonuçları ve Tartışma}

Uygulamalar java programlama dilinde NetBeans IDE 8.2 programı kullanılarak kodlanmıştır. Önerilen yöntem ile gerçekleştirilen uygulamalar sonucu oluşan yerleşim modelleri ile elde edilen yükseklik değerleri hesaplanmış ve bu modellerin optimal çözüme yakınlıkları incelenmiştir. Ayrıca çalışma, en uygun (Best-Fit/BF), meta-sezgisel yöntemlerden genetik algoritma ile alt-sol dolgu (Bottom-left fill) (GA+BLF), benzetimli tavlama ile alt-sol dolgu (Simulated Annealing/SA+BLF) ile yapılan çalışmalar ile karşılaştııılmış [11] ve problemdeki dikdörtgen sayısı arttıkça önerilen yöntemin daha etkin olduğu sonucu çıkarılmıştır. $C$ kategori, $P$ problem, $D S$ dikdörtgen sayısı, $H$ optimal yükseklik, ÖY önerilen yöntem sonucu elde edilen yükseklik değeri olmak üzere, $\mathrm{BF}, \mathrm{GA}+\mathrm{BLF}$ ve $\mathrm{SA}+\mathrm{BLF}$ sonucunda elde edilen yükseklik değerleri ile önerilen yöntem sonucunda elde edilen yükseklik değerlerinin karşılaştırılması Tablo 2'de ve optimal yükseklik değeri ile elde edilen yükseklik değerleri arasındaki fark ise Tablo 3 'te gösterilmektedir.

Tablo 2. Önerilen yöntem ile $G A+B L F, S A+B L F$ ve BF karşılaştırılması

\begin{tabular}{|c|c|c|c|c|c|c|c|}
\hline$C$ & $P$ & $D S$ & $H$ & $\begin{array}{c}G A \\
+ \\
B L F[11]\end{array}$ & $\begin{array}{c}\text { SA } \\
+ \\
B L F[11]\end{array}$ & $B F[11]$ & $\ddot{O Y}$ \\
\hline \multirow{3}{*}{$C 1$} & $P 1$ & 16 & 20 & 20 & 20 & 21 & 21 \\
\hline & $P 2$ & 17 & 20 & 21 & 21 & 22 & 22 \\
\hline & $P 3$ & 16 & 20 & 20 & 20 & 24 & 21 \\
\hline \multirow{3}{*}{$C 2$} & $P 1$ & 25 & 15 & 16 & 16 & 16 & 17 \\
\hline & $P 2$ & 25 & 15 & 16 & 16 & 16 & 17 \\
\hline & $P 3$ & 25 & 15 & 16 & 16 & 16 & 16 \\
\hline \multirow{3}{*}{$C 3$} & $P 1$ & 28 & 30 & 32 & 32 & 32 & 32 \\
\hline & $P 2$ & 29 & 30 & 32 & 32 & 34 & 33 \\
\hline & $P 3$ & 28 & 30 & 32 & 32 & 33 & 31 \\
\hline \multirow{3}{*}{ C4 } & $P 1$ & 49 & 60 & 64 & 64 & 63 & 62 \\
\hline & $P 2$ & 49 & 60 & 63 & 64 & 62 & 62 \\
\hline & $P 3$ & 49 & 60 & 62 & 63 & 62 & 62 \\
\hline \multirow{3}{*}{ C5 } & $P 1$ & 72 & 90 & 95 & 94 & 93 & 93 \\
\hline & $P 2$ & 73 & 90 & 95 & 95 & 92 & 92 \\
\hline & $P 3$ & 72 & 90 & 95 & 95 & 93 & 93 \\
\hline \multirow{3}{*}{ C6 } & $P 1$ & 97 & 120 & 127 & 127 & 123 & 123 \\
\hline & $P 2$ & 97 & 120 & 126 & 126 & 122 & 122 \\
\hline & $P 3$ & 97 & 120 & 126 & 126 & 124 & 124 \\
\hline \multirow{3}{*}{$C 7$} & $P 1$ & 196 & 240 & 255 & 255 & 247 & 244 \\
\hline & $P 2$ & 197 & 240 & 251 & 253 & 244 & 243 \\
\hline & P3 & 196 & 240 & 254 & 255 & 245 & 244 \\
\hline
\end{tabular}


European Journal of Science and Technology

Tablo 3. GA+BLF, SA+BLF, BF ve ÖY yükseklik değerlerinin optimal çözüme yakınlıkları

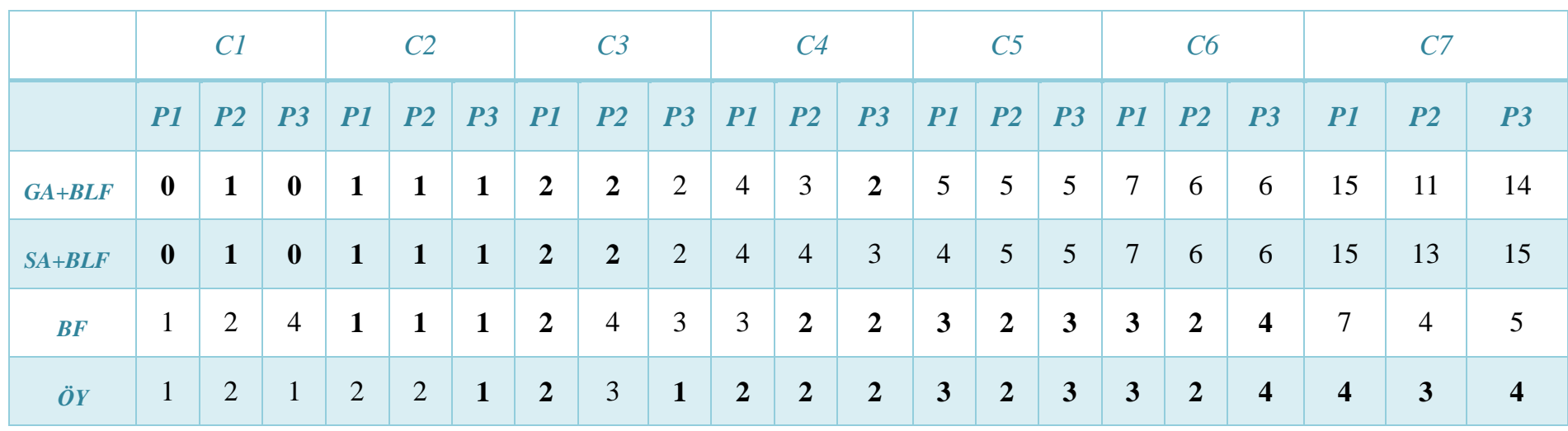

Tablo 3’te GA+BLF, SA+BLF, BF ve ÖY yöntemlerinde elde edilen yükseklik değerleri ile optimal çözüm yükseklik değerleri arasındaki farka bakıldığında parça sayısı arttıkça önerilen yöntemin daha etkin olduğu gözlemlenmektedir.

Hopper ve Turton veri seti üzerinde geliştirilen uygulamalar sonucunda elde edilen örnek paketleme düzenlerinin bazıları Şekil 6'da ve C6-P1 için de Şekil 7'de gösterilmektedir.

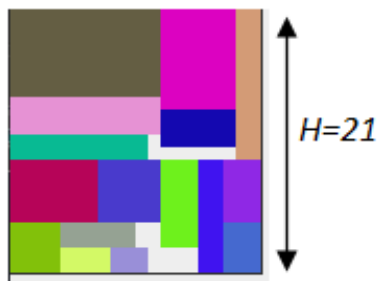

C1-P1 $(n=16)$

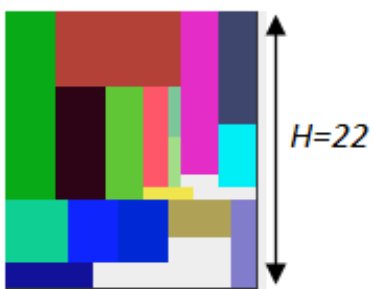

$C 1-P 2(n=17)$

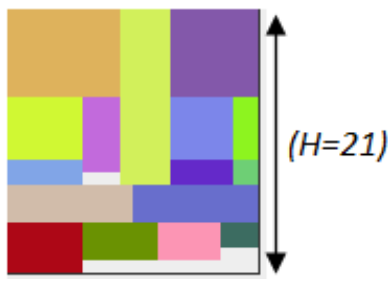

C1-P3 (n=16)

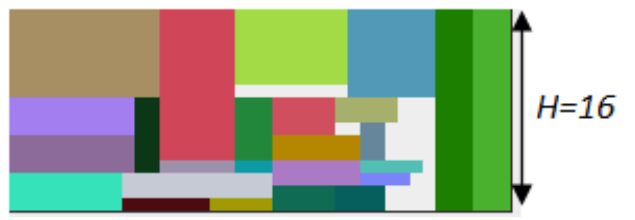

$C 2-P 3(n=25)$

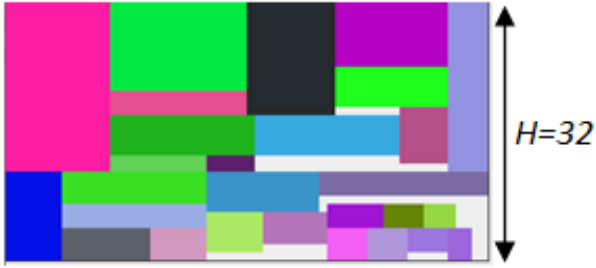

$C 3-P 1(n=28)$

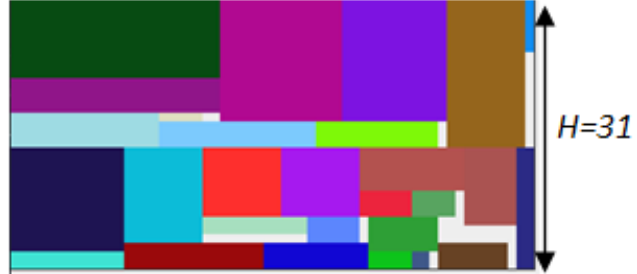

$C 3-P 3(n=28)$

Şekil 6. Geliştirilen örnek uygulamaların paketleme düzeni 


\section{Sonuç}

$\mathrm{Bu}$ çalı̧̧mada, iki boyutlu dikdörtgen şerit paketleme problemine alt sol dolgu, uygun olmayan çokgen ve ilk uygun azalan sezgisel yöntemleri kullanılarak çözüm sunulmuştur. Geliştirilen yöntem, literatürden alınan bir dizi örnek üzerinde test edilmiş̧tir ve bazı sezgisel (BF) ve meta-sezgisel (GA+BLF ve SA+BLF) yöntemler kullanılarak yapılan çalışmalar ile karşılaştırılmıştır ve optimal yükseklik değerine yakınlıkları incelenmiştir. Deneysel sonuçlar, geliştirilen yöntem ile yapılan çalışmaların BF, GA+BLF ve SA+BLF ile yapılan çalışmalar sonucunda elde edilen yükseklik değerlerine yakın sonuçların olduğu gözlemlenmiştir. Dikdörtgen sayısı arttıkça, geliş̧irilen yöntemin daha etkin olduğu sonucu çıkarılmıştır.

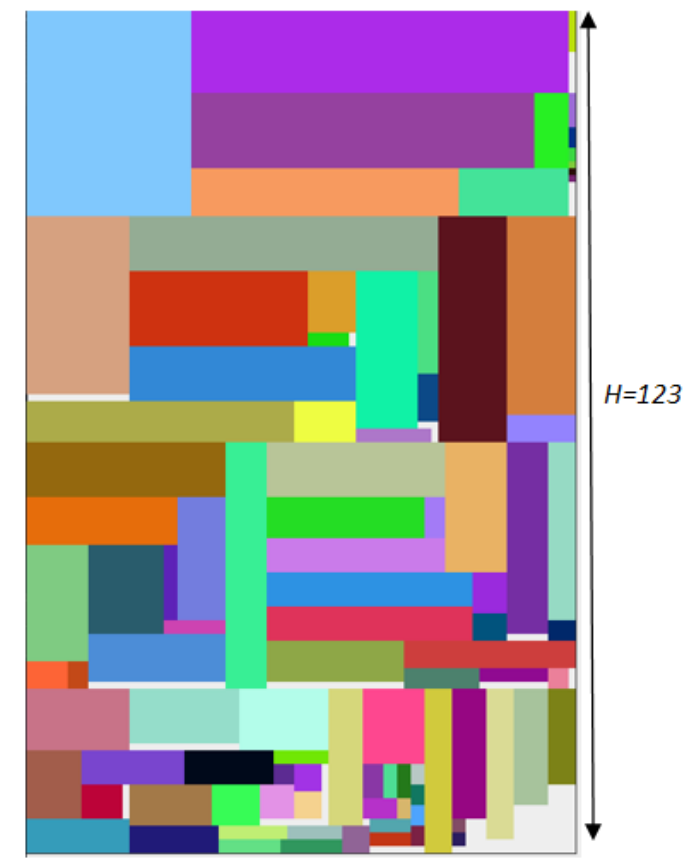

Şekil 7. Önerilen yöntem için C6-P1 (n=97) paketleme sonucu

\section{Kaynakça}

[1] A. Neuenfeldt, The Two-Dimensional Rectangular Strip Packing Problem, :December 2017 (2017).

[2] D. Zhang, L. Shi, S. C. H. Leung, and T. Wu, A priority heuristic for the guillotine rectangular packing problem, Information Processing Letters, 116:1 (2016) 15-21.

[3] G. Wäscher, H. Haußner, and H. Schumann, An improved typology of cutting and packing problems, European Journal of Operational Research, 183:3 (2007) 1109-1130.

[4] D. Zhang, Y. Kang, and A. Deng, A new heuristic recursive algorithm for the strip rectangular packing problem, Computers and Operations Research, 33:8 (2006) 2209-2217.

[5] D. Zhang, L. Wei, S. C. H. Leung, and Q. Chen, A binary search heuristic algorithm based on randomized local search for the rectangular strip-packing problem, INFORMS Journal on Computing, 25:2 (2013) 332-345.

[6] V. M. Kotov and D. Cao, A heuristic algorithm for the non-oriented 2D rectangular strip packing problem, Buletinul Academiei de Stiinte a Republicii Moldova. Matematica, 66:2 (2011) 81-88.

[7] I. Babaoğlu, Solving 2D strip packing problem using fruit fly optimization algorithm, Procedia Computer Science, 111:2015 (2017) 52-57.

[8] E. Hopper and B. C. H. Turton, Empirical investigation of meta-heuristic and heuristic algorithms for a 2D packing problem, European Journal of Operational Research, 128:1 (2001) 34-57.

[9] K. Daoden and T. Thaiupathump, Applying shuffled frog leaping algorithm and bottom left fill algorithm in rectangular packing problem, Proceedings of 2017 IEEE 7th International Conference on Electronics Information and Emergency Communication, ICEIEC 2017, July 2017 (2017) 136-139.

[10] E. Albayrak, İki boyutlu dikdörtgen şekilli stok kesme problemleri için sezgisel-metasezgisel algoritma ve yazılım geliştirme, Balikesir, ocak - 2013, (2013)

[11] E. K. Burke, G. Kendall, and G. Whitwell, A New Placement Heuristic for the Orthogonal Stock-Cutting Problem, Operations Research, 52:4 (2004) 655-671. 